\title{
Correction to: Complete mucosal healing of distal lesions induced by twice-daily budesonide 2 -mg foam promoted clinical remission of mild-to-moderate ulcerative colitis with distal active inflammation: double-blind, randomized study
}

\author{
Makoto Naganuma ${ }^{1} \cdot$ Nobuo Aoyama ${ }^{2} \cdot$ Tomohiro Tada $^{3} \cdot$ Kiyonori Kobayashi $^{4}$. \\ Fumihito Hirai $^{5} \cdot$ Kenji Watanabe $^{6} \cdot$ Mamoru Watanabe $^{7} \cdot$ Toshifumi Hibi $^{8}$
}

Published online: 13 October 2017

(C) Japanese Society of Gastroenterology 2017

Correction to: J Gastroenterol

\section{DOI 10.1007/s00535-017-1376-4}

In Fig. 2(c) of this article, the length of the "95\% CI difference bars" under the items labelled "Left-sided and Pancolitis" and "Left-sided" under the heading "Disease type" was corrected. The correct figure is shown in the following page.

The online version of the original article can be found under doi:10.1007/s00535-017-1376-4

Makoto Naganuma

maknaganuma@gmail.com

1 Department of Gastroenterology and Hepatology, School of Medicine, Keio University, Shinanomachi 35, Shinjuku-ku, Tokyo 160-0016, Japan

2 Gastrointestinal Endoscopy and Inflammatory Bowel Disease Center, Aoyama Medical Clinic, Hyogo, Japan

3 Tada Tomohiro Institute of Gastroenterology and Proctology, Saitama, Japan

4 Department of Research and Development Center for New Medical Frontiers, School of Medicine, Kitasato University, Kanagawa, Japan

5 Department of Gastroenterology, Fukuoka University Chikushi Hospital, Fukuoka, Japan

6 Department of Gastroenterology, Osaka City General Hospital, Osaka, Japan

7 Department of Gastroenterology and Hepatology, School of Medicine, Tokyo Medical and Dental University, Tokyo, Japan

8 Center for Advanced IBD Research and Treatment, Kitasato Institute Hospital, Kitasato University, Tokyo, Japan 


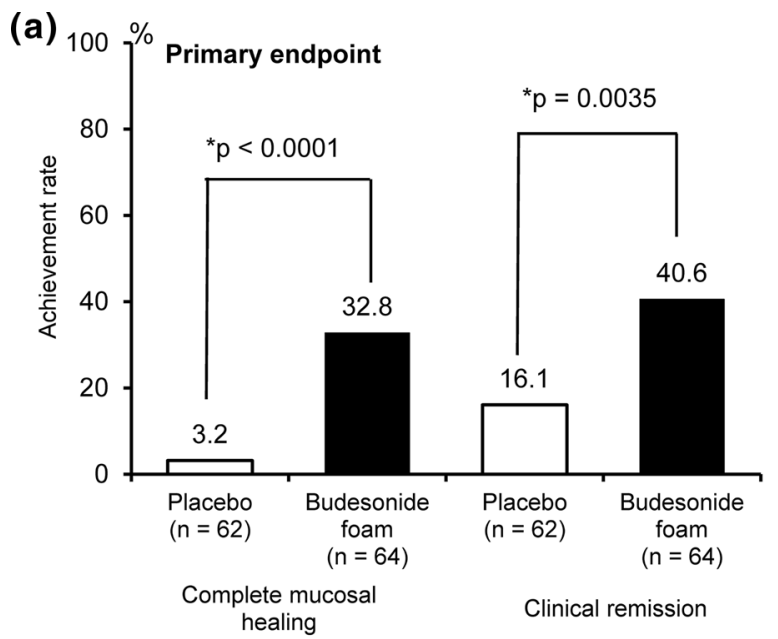

(b)

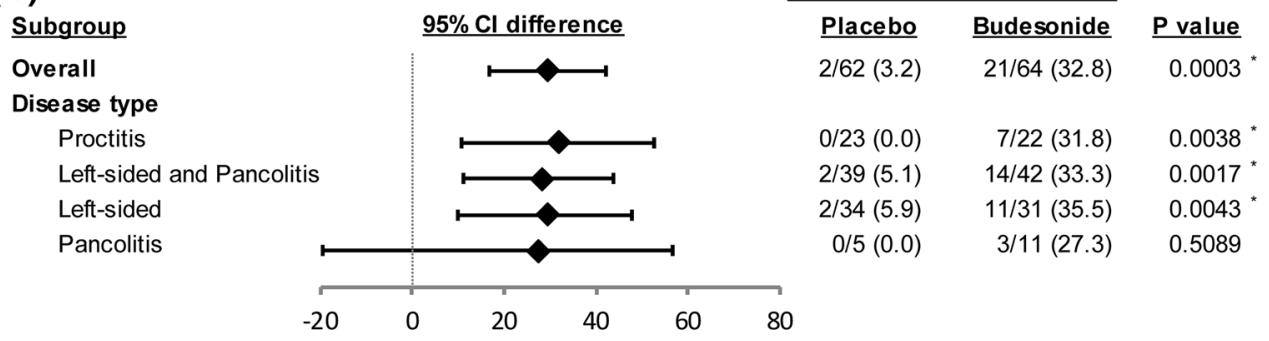

(c)

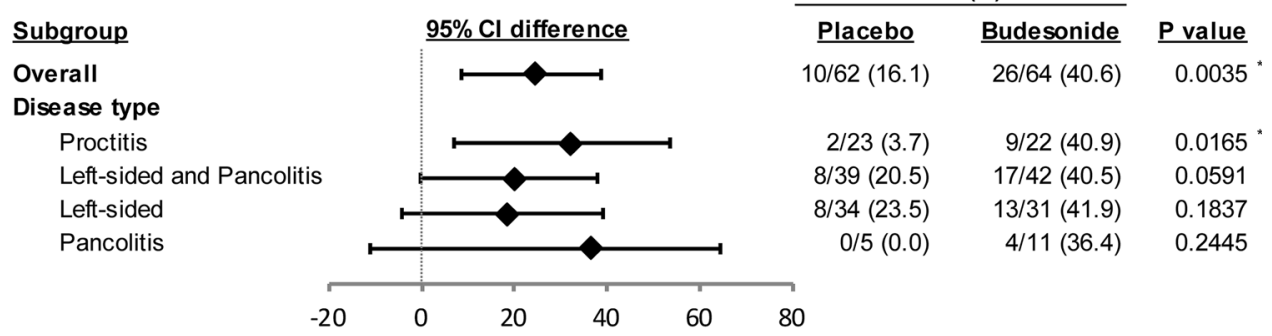

(d)

\begin{tabular}{llccccc}
\hline & \multicolumn{5}{c}{ Clinical remission, $\mathrm{n} / \mathrm{N}(\%)$} \\
\cline { 3 - 6 } & & Overall & Proctitis & Left-sided/Pancolitis & Left-sided & Pancolitis \\
\hline \multirow{2}{*}{$\begin{array}{l}\text { Complete } \\
\text { mucosal healing }\end{array}$} & Achieved & $16 / 21(76.2)$ & $5 / 7(71.4)$ & $11 / 14(78.6)$ & $9 / 11(81.8)$ & $2 / 3(66.7)$ \\
& Not achieved & $11 / 43(25.6)$ & $5 / 15(33.3)$ & $6 / 28(21.4)$ & $4 / 20(20.0)$ & $6 / 28(21.4)$ \\
\hline
\end{tabular}

In Fig. 3(a) of this article, the length of the "95\% CI difference bar" for the items labelled "Yes" under the heading "Rectal 5-ASA" was corrected. In Fig. 3(b), the length of the "95\% CI difference bars" for the items labelled "Yes" under the heading "Rectal 5-ASA", the item "Low" under the heading "Dose of oral 5-ASA", and the item " $6 \leq$ " under the heading "Baseline MMDAI" was corrected. The correct figure is shown in the following page. 
(a) Subgroup

Overall

Rectal 5-ASA

No

Yes

Dose of oral 5-ASA

Low

High

Baseline MMDAl

$\leq 5$

$6 \leq$

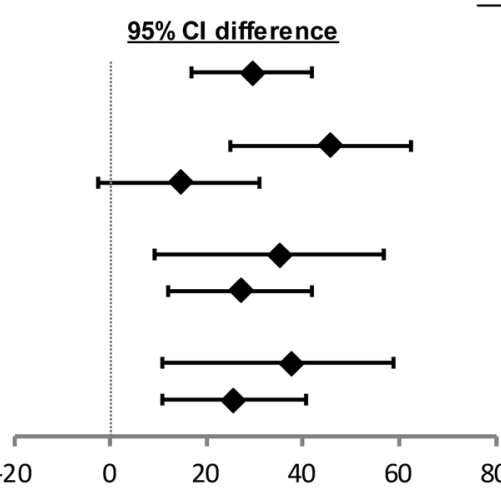

(b)

Subgroup

Overall

Rectal 5-ASA

No

Yes

Dose of oral 5-ASA

Low

High

Baseline MMDAl

$\leq 5$

$6 \leq$
n/N (\%)

\begin{tabular}{|c|c|c|}
\hline Placebo & Budesonide & $\underline{P \text { value }}$ \\
\hline $2 / 62(3.2)$ & $21 / 64(32.8)$ & 0.0003 * \\
\hline $1 / 34(2.9)$ & $15 / 31(48.4)$ & 0.0001 * \\
\hline $1 / 28(3.6)$ & $6 / 33(18.2)$ & 0.1121 \\
\hline $1 / 20(5.0)$ & $8 / 20(40.0)$ & $0.0197^{*}$ \\
\hline $1 / 42(2.4)$ & $13 / 44(29.6)$ & $<0.0001$ * \\
\hline $1 / 19(5.3)$ & $9 / 21(42.9)$ & 0.0094 * \\
\hline $1 / 43$ (2.3) & $12 / 43(27.9)$ & 0.0016 * \\
\hline
\end{tabular}

n/N (\%)

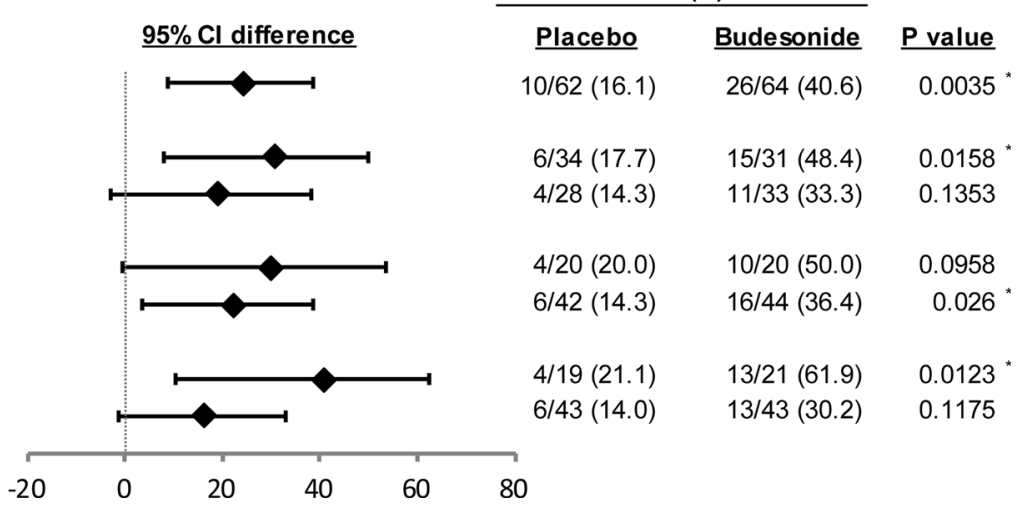

